\title{
Biosynthesis of Bile Acids in Cerebrotendinous Xanthomatosis Relationship of Bile Acid Pool Sizes and Synthesis Rates to Hydroxylations at C-12, C-25, and C-26
}

Gerald Salen, Sarah Shefer, G. S. Tint, G. Nicolau, B. Dayal, and A. K. Batta

Gastroenterology Section, Veterans Administration Medical Center, East Orange, New Jersey 07019; and Department of Medicine, University of Dentistry and Medicine of New Jersey-New Jersey Medical School, Newark, New Jersey 07103

\begin{abstract}
To examine the defect in side-chain oxidation during the formation of bile acids in cerebrotendinous xanthomatosis, we measured in vitro hepatic microsomal hydroxylations at C-12 and C-25 and mitochondrial hydroxylation at C-26 and related them to the pool size and synthesis rates of cholic acid and chenodeoxycholic acid as determined by the isotope dilution technique. Hepatic microsomes and mitochondria were prepared from seven subjects with cerebrotendinous xanthomatosis and five controls. Primary bile acid synthesis was markedly reduced in cerebrotendinous xanthomatosis as follows: cholic acid, $133 \pm 30$ vs. $260 \pm 60 \mathrm{mg} / \mathrm{d}$ in controls; and chenodeoxycholic acid, $22 \pm 10$ vs. $150 \pm 30 \mathrm{mg} / \mathrm{d}$ in controls. As postulated for chenodeoxycholic acid synthesis, mitochondrial 26-hydroxylation of $5 \beta$-cholestane-3 $\alpha, 7 \alpha$-diol was present in all specimens and was 30-fold more active than the corresponding microsomal 25-hydroxylation. However, mean mitochondrial 26-hydroxylation of $5 \beta$-cholestane-3 $\alpha, 7 \alpha$-diol was less active in cerebrotendinous xanthomatosis than in controls: 59 \pm 17 compared with $126 \pm 21 \mathrm{pmol} / \mathrm{mg}$ protein per min. As for cholic acid synthesis, microsomal 25-hydroxylation of $5 \beta$-cholestane$3 \alpha, 7 \alpha, 12 \alpha$-triol was substantially higher in cerebrotendinous xanthomatosis and control preparations (620 \pm 103 and 515 \pm 64 $\mathrm{pmol} / \mathrm{mg}$ protein per min, respectively) than the corresponding control mitochondrial 26-hyroxylation of the same substrate (165 $\pm 25 \mathrm{pmol} / \mathrm{mg}$ protein per $\mathrm{min}$ ). Moreover in cerebrotendinous xanthomatosis, mitochondrial $5 \beta$-cholestane-3 $\alpha, 7 \alpha, 12 \alpha$ triol-26-hydroxylase activity was one-seventh as great as in controls. Hepatic microsomal $12 \alpha$-hydroxylation, which may be rate-controlling for the cholic acid pathway, was three times more active in cerebrotendinous xanthomatosis than in controls: 1,600 vs. $500 \mathrm{pmol} / \mathrm{mg}$ protein per min. These results demonstrate severely depressed primary bile acid synthesis in cerebrotendinous xanthomatosis with a reduction in chenodeoxycholic acid formation and pool size disproportionately greater than that for cholic acid. The deficiency of chenodeoxycholic acid can be accounted for by hyperactive microsomal $12 \alpha$ hydroxylation that diverts precursors into the cholic acid pathway combined with decreased side-chain oxidation (mitochondrial 26-hydroxylation). However, side-chain oxidation in cholic acid biosynthesis may be initiated via microsomal 25 hydroxylation of $5 \beta$-cholestane-3 $\alpha, 7 \alpha, 12 \alpha$-triol, since the corresponding mitochondrial 26 -hydroxylation of $5 \beta$-cholestane-
\end{abstract}

Received for publication 28 September 1984 and in revised form 11 March 1985.

J. Clin. Invest.

(C) The American Society for Clinical Investigation, Inc.

0021-9738/85/08/0744/08 $\$ 1.00$

Volume 76, August 1985, 744-751
$3 \alpha, 7 \alpha, 12 \alpha$-triol was substantially lower in control and cerebrotendinous xanthomatosis liver. Thus, separate mechanisms may exist for the cleavage of the cholesterol side chain in cholic acid and chenodeoxycholic acid biosynthesis.

\section{Introduction}

Cholic acid ${ }^{1}$ and chenodeoxycholic acid are primary bile acids produced in the liver of humans and most mammals. Both bile acids are similar in structure, differing only in the number of ring hydroxyl groups. Although arising from the same precursor, cholesterol (I) (see Fig. 1), and sharing several early formative steps, their respective synthetic pathways diverge after the introduction of the $12 \alpha$-hydroxyl group into $7 \alpha$ hydroxy-4-cholesten-3-one (III) to form $7 \alpha, 12 \alpha$-dihydroxy-4cholesten-3-one (VIII) (1). The latter precursor is totally committed to cholic acid synthesis. Accordingly, the enzyme that catalyzes $12 \alpha$-hydroxylation (7 $\alpha$-hydroxy-4-cholesten-3-one$12 \alpha$-hydroxylase) may control, in part, the relative proportions of cholic acid and chenodeoxycholic acid that are found in the enterohepatic pool.

Recently, defective bile acid metabolism has been discovered in the rare inherited lipid storage disease, cerebrotendinous xanthomatosis $(\text { CTX })^{2}(2)$. The abnormalities include a marked deficiency of chenodeoxycholic acid in the bile and the excretion of large quantities of bile alcohols that contained 27 carbons in the bile, urine, and feces (3-7). Virtually all of these bile alcohols are hydroxylated at C-12 and C-25 and when excreted in urine and bile are conjugated at $\mathrm{C}-3$ with glucuronic acid $(6,7)$. Total bile acid synthesis as measured by the sterol balance method was reduced $50 \%$ (8). Although the exact enzymatic defect in bile acid synthesis in CTX has not been defined completely, the major biochemical abnormality apparently involves the incomplete oxidation of the cholesterol side chain (4). The accumulation of $C_{27}$ bile alcohols that are $12 \alpha$ hydroxylated suggests that cholic acid synthesis is impaired, while the deficiency of chenodeoxycholic acid in the bile points to reduced formation of this primary bile acid. Recently, Oftebro and co-workers $(9,10)$ have reported that hepatic mitochondrial 26-hydroxylase activity, the putative initial reaction for side-chain oxidation in both cholic and chenodeoxycholic acid synthesis, was completely absent from the liver

1. The following common names have been substituted for the systematic names in this paper: cholesterol, 5-cholesten-3 $\beta$-ol; cholestanol, $5 \alpha$-cholestan-3 $\beta$-ol; cholic acid, $3 \alpha, 7 \alpha, 12 \alpha$-trihydroxy- $5 \beta$-cholan-24oic acid; chenodeoxycholic acid, $3 \alpha, 7 \alpha$-dihydroxy-5 $\beta$-cholan-24-oic acid; deoxycholic acid, $3 \alpha, 12 \alpha$-dihydroxy-5 $\beta$-cholan-24-oic acid; lithocholic acid, $3 \alpha$-hydroxy-5 $\beta$-cholan-24-oic acid.

2. Abbreviations used in this paper: CTX, cerebrotendinous xanthomatosis; GLC, gas-liquid chromatography; $R_{f}$, retension flow; TLC, thin-layer chromatography. 
of a single CTX subject. This enzyme catalyzes the conversion of $5 \beta$-cholestane- $3 \alpha, 7 \alpha, 12 \alpha$-triol (IX) and $5 \beta$-cholestane- $3 \alpha, 7 \alpha$ diol (IV) into $5 \beta$-cholestane-3 $\alpha, 7 \alpha, 12 \alpha, 26$-tetrol (XI) and $5 \beta$ cholestane-3 $\alpha, 7 \alpha, 26$-triol (V), which are the respective first putative precursors in the oxidation of the sterol side chain to a carboxylic acid in the formation of cholic acid and chenodeoxycholic acid (1) (Figs. 1 and 2). As a consequence, these investigators $(9,10)$ believe that absent mitochondrial 26hydroxylase activity is the inherited enzymatic abnormality in CTX, responsible for deficient primary bile acid synthesis. However, a different explanation for the defect in side-chain oxidation in bile acid synthesis in this disease has been proposed by Salen and co-workers $(11,12)$. These workers suggested that side-chain cleavage in cholic acid synthesis occurs mainly via precursors hydroxylated at C-25 (Fig. 2); and they have discovered that in CTX there is a significant deficiency of the microsomal enzyme that stereospecifically hydroxylates $5 \beta$-cholestane-3 $\alpha, 7 \alpha, 12 \alpha, 25$-tetrol (XIV) at $24 S$

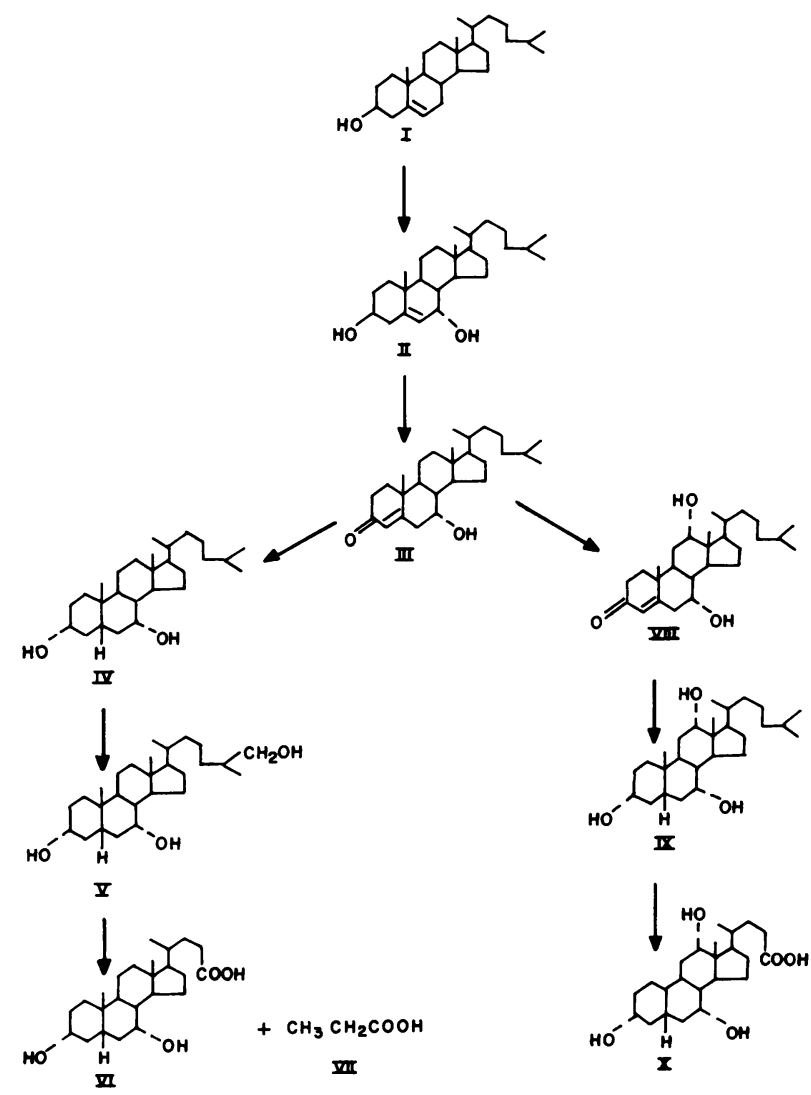

Figure 1. Cholic acid and chenodeoxycholic biosynthetic pathway. Cholesterol (I) is transformed to $7 \alpha$-hydroxycholesterol (II), which is converted to $7 \alpha$-hydroxy-4-cholesten-3-one (III) by microsomal enzymes that are intermediates common to both pathways. In chenodeoxycholic acid synthesis, $7 \alpha$-hydroxy-4-cholesten-3-one (III) is reduced to $5 \beta$-cholestane- $3 \alpha, 7 \alpha$-diol (IV) by cytosolic enzymes, which is then converted to $5 \beta$-cholestane-3 $\alpha, 7 \alpha, 26$-triol (V) by mitochondria. The latter intermediate $(\mathrm{V})$ is then transformed to chenodeoxycholic acid (VI) and propionic acid (VII). In cholic acid biosynthesis, $7 \alpha$-hydroxy-4-cholesten-3-one (III) is $12 \alpha$-hydroxylated by microsomal enzymes to yield $7 \alpha, 12 \alpha$-dihydroxy-4-cholesten-3-one (VIII), which is reduced to $5 \beta$-cholestane- $3 \alpha, 7 \alpha, 12 \alpha$-triol (IX) by cytosolic enzymes. The latter compound is transformed to cholic acid (X) via the pathways illustrated in Fig. 2.
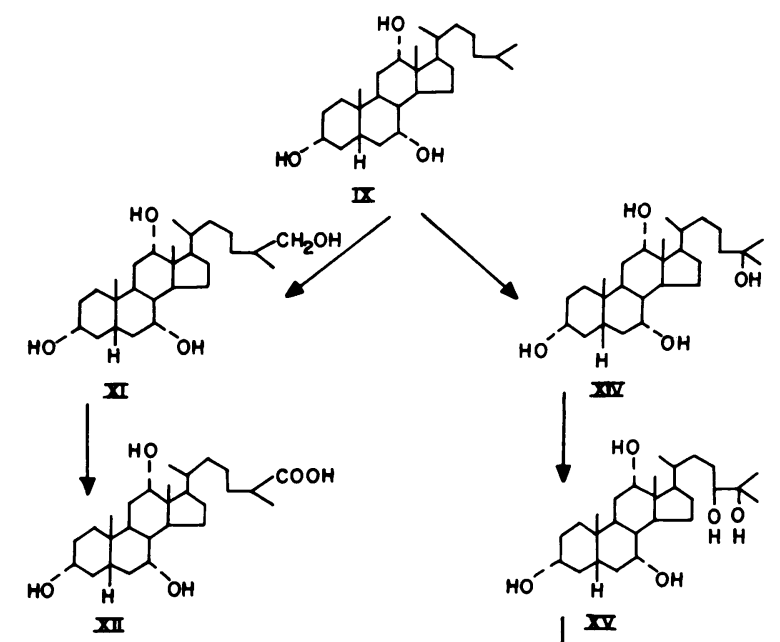

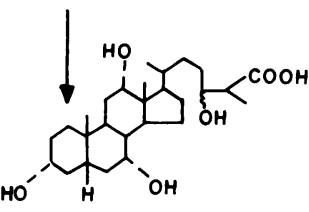

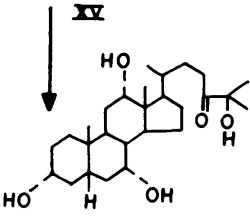

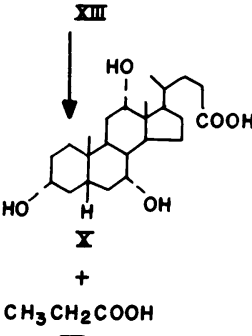

III

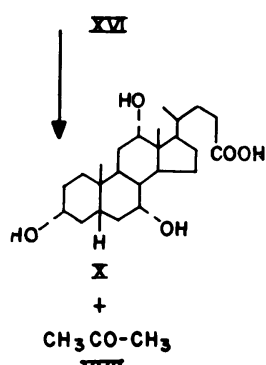

IXII

Figure 2. Pathways for side-chain cleavage in cholic acid biosynthesis. $5 \beta$-Cholestane- $3 \alpha, 7 \alpha, 12 \alpha$-triol (IX) is an obligatory precursor in cholic acid synthesis. In the "classical pathway," this intermediate (IX) is hydroxylated at C-26 by mitochondrial enzymes to yield $5 \beta$ cholestane-3 $\alpha, 7 \alpha, 12 \alpha, 26$-tetrol (XI), which is oxidized by cytosolic enzymes to yield $3 \alpha, 7 \alpha, 12 \alpha$-trihydroxycoprostan-26-oic acid (XII). This precursor (XII) is hydroxylated at C-24 by microsomes to form $3 \alpha, 7 \alpha, 12 \alpha, 24 \xi$-tetrahydroxycoprostan-26-oic acid (XIII), which is cleaved by mitochondrial or cytosolic enzymes to give cholic acid (X) and propionic acid (VII). The alternate 25-hydroxylation pathway begins with the 25 -hydroxylation of $5 \beta$-cholestane- $3 \alpha, 7 \alpha, 12 \alpha$-triol (IX) by microsomal enzymes to form $5 \beta$-cholestane- $3 \alpha, 7 \alpha, 12 \alpha, 25$ tetrol (XIV). This intermediate (XIV) undergoes stereospecific hydroxylation at $\mathrm{C}-24$ also by microsomal enzymes to yield $5 \beta$-cholestane-3 $\alpha, 7 \alpha, 12 \alpha, 24 \mathrm{~S}, 25$-pentol (XV), which is oxidized at C-24 to give $3 \alpha, 7 \alpha, 12 \alpha, 25$-tetrahydroxy-5 $\beta$-cholestan-24-one (XVI). The latter 24oxo-precursor (XVI) is cleaved by cytosolic enzymes to yield cholic acid $(\mathrm{X})$ and acetone (XVII).

to form $5 \beta$-cholestane-3 $\alpha, 7 \alpha, 12 \alpha, 24 \mathrm{~S}, 25$-pentol (XV). As a result of this enzymatic block, which they believe is the principal inherited abnormality in CTX, cholic acid synthesis is impaired and precursors that are proximal to the defect and their metabolites then accumulate. The profound deficiency of chenodeoxycholic acid in CTX may result from the diversion of precursors from chenodeoxycholic acid into the cholic acid pathway (2).

In this study, we examined key reactions in the microsomal and mitochondrial 25- and 26-hydroxylation pathways in the formation of both primary bile acids. The pool sizes and 
synthesis rates of cholic acid and chenodeoxycholic acid were measured in CTX and control subjects and compared with the in vitro activities of the hepatic hydroxylating enzymes: microsomal $7 \alpha$-hydroxy-4-cholesten-3-one-12 $\alpha$-hydroxylase

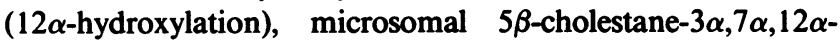
triol-25-hydroxylase, $5 \beta$-cholestane- $3 \alpha, 7 \alpha$-diol-25-hydroxylase (microsomal 25-hydroxylation), mitochondrial 5 $\beta$-cholestane$3 \alpha, 7 \alpha, 12 \alpha$-triol-26-hydroxylase, and $5 \beta$-cholestane- $3 \alpha, 7 \alpha$-diol26-hydroxylase (mitochondrial 26-hydroxylation). Our aim was to relate quantitative measurements of primary bile acid synthesis in CTX and control subjects to the mechanism of side-chain cleavage.

\section{Methods}

Clinical. Studies were conducted in seven control and eight CTX subjects. Brief descriptions of the CTX subjects are included in Table I. All studies were conducted at the Veterans Administration Medical Center, East Orange, NJ. Cholic acid and chenodeoxycholic acid pool sizes and production rates were determined by the isotope dilution method described by Lindstedt (13). In this experiment, three CTX and seven control subjects received $10 \mu \mathrm{Ci}\left[24^{14} \mathrm{C}\right]$ cholic acid and 10 $\mu \mathrm{Ci}\left[24-{ }^{14} \mathrm{C}\right]$ chenodeoxycholic acid intravenously and bile was collected daily for the next $4 \mathrm{~d}$. Bile acid pool sizes and production rates were calculated from the respective cholic acid and chenodeoxycholic acid specific activity decay curves (13). Percutaneous needle liver biopsies were required from the CTX subjects as part of their diagnostic medical work up and a portion of the biopsy was used for enzyme

Table I. Clinical Data-CTX Subjects

\begin{tabular}{|c|c|c|c|c|c|}
\hline Patient & Sex & Age & Height & Weight & Disability \\
\hline & & & $\mathrm{cm}$ & $\mathrm{kg}$ & \\
\hline 1. J.C. & $\mathbf{M}$ & 39 & 169 & 59 & $\begin{array}{l}\text { Achilles tendon xanthomas, } \\
\text { increased deep tendon } \\
\text { reflexes }\end{array}$ \\
\hline 2. E.D.S. & $\mathbf{F}$ & 59 & 161 & 47 & $\begin{array}{l}\text { Achilles tendon xanthomas, } \\
\text { increased deep tendon } \\
\text { reflexes }\end{array}$ \\
\hline 3. E.D.E. & $\mathbf{F}$ & 57 & 169 & 59 & $\begin{array}{l}\text { Achilles tendon xanthomas, } \\
\text { spastic quadriplegia }\end{array}$ \\
\hline 4. G.A. & $\mathbf{F}$ & 60 & 150 & 55 & $\begin{array}{l}\text { Dementia, tendon xanthomas, } \\
\text { cataracts, spinal cord } \\
\text { paresis, cerebellar ataxia }\end{array}$ \\
\hline 5. W.H. & $\mathbf{M}$ & 54 & 165 & 68 & $\begin{array}{l}\text { Dementia, Achilles tendon } \\
\text { xanthomas, xanthelasthma, } \\
\text { spinal cord paresis, } \\
\text { cerebellar ataxia }\end{array}$ \\
\hline 6. A.B. & $\mathbf{F}$ & 59 & 153 & 52 & $\begin{array}{l}\text { Dementia, spinal cord paresis, } \\
\text { cerebellar ataxia, cataracts }\end{array}$ \\
\hline 7. P.T. & $\mathbf{F}$ & 49 & 158 & 50 & $\begin{array}{l}\text { Dementia, spinal cord paresis, } \\
\text { cataracts, cerebellar ataxia, } \\
\text { Achilles tendon xanthomas }\end{array}$ \\
\hline 8. L.M. & $\mathbf{F}$ & 30 & 150 & 48 & $\begin{array}{l}\text { Dementia, Achilles tendon } \\
\text { xanthomas, spinal cord } \\
\text { paresis, cataracts }\end{array}$ \\
\hline
\end{tabular}

assay and evaluated by electron microscopy. In control subjects, liver biopsies were needed to establish the medical diagnosis in cases of hepatomegaly or possible hepatic malignancy. If morphology was normal, a portion of the liver tissue was used for enzyme analyses. In all control cases, liver function tests and biliary bile composition were normal (Table II). The experimental protocols were approved by the Human Studies Committees of the Veterans Administration Hospital, East Orange, NJ, and the University of Medicine and Dentistry of New Jersey-New Jersey Medical School, Newark, NJ.

Biliary bile acid and bile alcohol analyses. Samples $(1-2 \mathrm{ml})$ of intestinal bile were analyzed for bile acid and bile alcohol composition by the method of Salen et al. $(8,11)$. Briefly, after extraction of cholesterol, the free bile acids were methylated, then silylated, and total bile acid and bile alcohol composition was determined by gasliquid chromatography (GLC) on columns packed with $1 \%$ HiEff 8 BP (Applied Science, State College, PA). On separate aliquots, methyl cholate (retension flow $\left.\left[R_{f}\right] \mathbf{0 . 3 0}\right)$ and methyl chenodeoxycholic $\left(R_{f}\right.$ 0.65 ) were isolated for radioactivity and mass measurements by thinlayer chromatography (TLC) on plates coated with Silica Gel H developed in choloroform/methanol/acetone (70:20:5 [vol/vol/vol]). An aliquot of each purified bile acid methyl ester was assayed for radioactivity in a liquid scintillation spectrometer (Beckman Instruments, Inc., Irvine, CA), and a second aliquot was silylated and quantitated by GLC.

\section{Radioactive compounds}

The [G- $\left.{ }^{3} \mathrm{H}\right] 7 \alpha$-hydroxy-4-cholesten-3-one was prepared from [G$\left.{ }^{3} \mathrm{H}\right]$ chenodeoxycholic acid by the method of Björkhem et al. (14). The specific activity was $44 \mu \mathrm{Ci} / \mathrm{mg}$ and the radioactive purity was $>98 \%$ when tested by TLC on plates coated with Silica Gel H in the solvent system, ethyl acetate/benzene (6:4 [ vol/vol]). Unlabeled $5 \beta$-cholestane$3 \alpha, 7 \alpha, 12 \alpha$-triol was prepared by electrolytic coupling of cholic acid with isovaleric acid according to Bergström and Krabisch (15) and specifically labeled $\left[7 \beta-{ }^{3} \mathrm{H}\right] 5 \beta$-cholestane- $3 \alpha, 7 \alpha, 12 \alpha$-triol was produced according to the method of Björkhem and Gustafsson (sp act $17 \mu \mathrm{Ci}$ / mg, radioactive purity $98 \%$ ) (16). Similarly, unlabeled $5 \beta$-cholestane$3 \alpha, 7 \alpha$-diol was prepared by the electrolytic coupling of chenodeoxycholic acid and isovaleric acid and was specifically labeled to form $\left[7 \beta-{ }^{3} \mathrm{H}\right] 5 \beta$ cholestane-3 $\alpha, 7 \alpha$-diol (16). $5 \beta$-Cholestane- $3 \alpha, 7 \alpha, 12 \alpha, 25$-tetrol and $5 \beta$ cholestane- $3 \alpha, 7 \alpha, 25 \alpha$-triol were prepared from cholic acid and chenodeoxycholic acid by the method of Dayal et al. (17) and purified

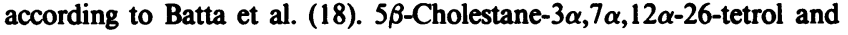
$5 \beta$-cholestane-3 $\alpha, 7 \alpha, 26$-triol were prepared by the reduction of both $3 \alpha, 7 \alpha, 12 \alpha$-trihydroxycoprostanoic acid and $3 \alpha, 7 \alpha$-dihydroxycoprostanoic acid, which were isolated from the bile of Alligator mississippiensis. $\left[24-{ }^{14} \mathrm{C}\right]$ Chenodeoxycholic acid and $\left[24-{ }^{14} \mathrm{C}\right]$ cholic acid were purchased from the New England Nuclear (Boston, MA). The radioactive bile acids were purified by TLC before their use and the final specific activities were $12 \mu \mathrm{Ci} / \mu \mathrm{mol}$ and $15 \mu \mathrm{Ci} / \mu \mathrm{mol}$, respectively.

Cofactors. NAD, NADP, NADPH, and D-glucose-6-phosphate dehydrogenase were purchased from Calbiochem-Behring Corp., San Diego, CA.

\section{Isolation of liver microsomes and mitochondria}

Liver specimens were obtained $\sim 10$ a.m. after at least a 12 -h fast to minimize possible effects of diurnal variation. It is assumed that bile acid synthesis and enzyme activity are lowest at this time. Tissue was minced with a razor blade and homogenized for $40 \mathrm{~s}$ in $0.25 \mathrm{M}$ sucrose (60 $\mathrm{mg}$ liver in $0.2 \mathrm{ml}$ ) and the mitochondrial and microsomal fractions were obtained as described by Shefer and co-workers $(19,20)$. The final mitochondrial and microsomal pellets were suspended in ice-cold $0.25 \mathrm{M}$ sucrose in a volume of $0.1 \mathrm{ml}$. The mitochondrial pellet was found to contain no more than $3 \%$ microsomes. From a $60-\mathrm{mg}$ liver specimen, a typical preparation had a concentration of 1-1.5 mg protein/0.1 $\mathrm{ml}$ as determined according to Lowry et al. (21).

\section{Enzyme assays}

Microsomal 25-hydroxylase activity. The assays were performed according to Shefer et al. (19). The complete system contained in a 
volume of $1.0 \mathrm{ml}: 85 \mathrm{mM}$ phosphate buffer, $\mathrm{pH} 7.4,1.7 \mathrm{mM} \mathrm{MgCl}_{2}$, $3 \mathrm{mM}$ NADPH, and $0.1 \mathrm{ml}$ of the microsomal fraction that contained $0.5-1 \mathrm{mg}$ protein. The reaction was initiated by the addition of 100 nmol of $\left[7 \beta-{ }^{3} \mathrm{H}\right] 5 \beta$-cholestane-3 $\alpha, 7 \alpha, 12 \alpha$-triol in $15 \mu$ l of acetone. In preliminary experiments, it was determined that the exogenous substrate exceeded the endogenous substrate by 300 times. The incubation mixture was shaken in air at $37^{\circ} \mathrm{C}$ for $15 \mathrm{~min}$ and the reaction was terminated by the addition of $0.1 \mathrm{ml}$ of $1 \mathrm{~N} \mathrm{HCl}$. All enzyme assays were carried out in duplicate and zero-time controls were run with each experiment. The reaction products were isolated after extraction with ethyl acetate and the pure biosynthetic $5 \beta$-cholestane- $3 \alpha, 7 \alpha, 12 \alpha, 25$ tetrol was obtained by TLC on plates coated with Silica Gel G developed three times in chloroform/acetone/methanol (70:50:2, [vol/ $\mathrm{vol} / \mathrm{vol}]), R_{f} 0.41$. Enzyme activities were then calculated by dividing the radioactivity of the $5 \beta$-cholestanetetrol by the specific activity of the substrate and were expressed as picomoles of product formed per milligram protein per minute.

The formation of $5 \beta$-cholestane- $3 \alpha, 7 \alpha, 25$-triol was assayed in a similar system, except that $100 \mathrm{nmol}$ of $\left[7 \beta-{ }^{3} \mathrm{H}\right] 5 \beta$-cholestane- $3 \alpha, 7 \alpha-$ diol (sp act $2.0 \times 10^{7} \mathrm{dpm} / \mu \mathrm{mol}$ ) was used as substrate and the product, $5 \beta$-cholestane-3 $\alpha, 7 \alpha, 25$-triol, was isolated by TLC on Silica Gel $G\left(R_{f} 0.56\right)$ developed twice in the solvent system chloroform/ acetone/methanol (70:50:2 [vol/vol/vol]) (18).

Mitochondrial 26-hydroxylase activity. Transformation of $5 \beta$-cholestane- $3 \alpha, 7 \alpha, 12 \alpha$-triol and $5 \beta$-cholestane- $3 \alpha, 7 \alpha$-diol into $5 \beta$-cholestane$3 \alpha, 7 \alpha, 12 \alpha, 26$-tetrol and $5 \beta$-cholestane- $3 \alpha, 7 \alpha, 26$-triol was performed according to the method of Shefer et al. (20). Briefly, the standard incubation mixture contained $85 \mathrm{mM}$ phosphate buffer ( $\mathrm{pH} 7.4), 1.7$ $\mathrm{mM} \mathrm{MgCl}, 4 \mathrm{mM} \mathrm{DL}$ isocitrate, and $0.1 \mathrm{ml}$ of the mitochondrial fraction that contained $0.5-1 \mathrm{mg}$ protein in a final volume of $1.0 \mathrm{ml}$ and was preincubated for $5 \mathrm{~min}$ at $37^{\circ} \mathrm{C}$. The reaction was then initiated by the addition of $100 \mathrm{nmol}$ of either $\left[7 \beta-{ }^{3} \mathrm{H}\right] 5 \beta$-cholestane$3 \alpha, 7 \alpha, 12 \alpha$-triol or $\left[7 \beta-{ }^{3} \mathrm{H}\right] 5 \beta$-cholestane- $3 \alpha, 7 \alpha$-diol in $15 \mu$ l acetone and incubated for an additional $15 \mathrm{~min}$ with gentle shaking in air. The reaction was stopped by the addition of $0.1 \mathrm{ml}$ of $1 \mathrm{~N} \mathrm{HCl}$ and the products and precursors extracted with ethyl acetate. The reaction products ( $5 \beta$-cholestane- $3 \alpha, 7 \alpha, 12 \alpha, 26$-tetrol or $5 \beta$-cholestane-3 $3 \alpha, 7 \alpha, 26$ triol) were isolated by TLC on Silica Gel G plates as described above for the 25-hydroxylated products: $5 \beta$-cholestane-3 $\alpha, 7 \alpha, 26$-triol $\left(R_{f}\right.$ $0.62)$ and $5 \beta$-cholestane- $3 \alpha, 7 \alpha, 12 \alpha, 26$-tetrol $\left(R_{f} 0.45\right)$. Enzyme activities were calculated in the same manner as the microsomal products.

\section{Microsomal 12a-hydroxylase activity}

The formation of $7 \alpha, 12 \alpha$-dihydroxy-4-cholesten-3-one from $7 \alpha$-hydroxy4-cholesten-3-one by hepatic microsomes was assayed by the method of Nicolau et al. (22). [7 $\left.\beta-{ }^{3} \mathrm{H}\right] 7 \alpha$-Hydroxy-4-cholesten-3-one (100 $\mathrm{nmol}$ ) was solubilized in $50 \mu \mathrm{l}$ acetone and preincubated at room temperature for $10 \mathrm{~min}$ with $0.3 \mathrm{ml}$ of a solution containing $0.6 \mathrm{mg}$ bovine serum albumin. The standard assay system contained, in a volume of $2.2 \mathrm{ml}$, the following: solubilized substrate $(100 \mathrm{nmol} / 0.3$ $\mathrm{ml}), 0.5 \mathrm{ml}$ of microsomal suspension, $1.0 \mathrm{ml}$ of NADPH generating system (70 mM phosphate buffer, pH 7.4, $2.25 \mathrm{mM} \mathrm{MgCl}, 1.25 \mathrm{mM}$ NADP, $2.5 \mathrm{nM}$ glucose 6-phosphate, and $5 \mathrm{U}$ glucose-6-phosphate dehydrogenase) and $0.4 \mathrm{ml}$ of homogenizing medium ( $0.3 \mathrm{M}$ sucrose, $75 \mathrm{mM}$ nicotinamide, $2 \mathrm{mM}$ EDTA, and $20 \mathrm{mM}$ mercaptoethanol). Incubations were terminated by the addition of $2 \mathrm{ml}$ methanol and the reaction products extracted with chloroform/methanol (3:1 [ $\mathrm{vol} /$ vol]). After TLC on Silica Gel G plates developed with ethyl acetate/ benzene (6:4 [vol/vol]), $7 \alpha, 12 \alpha$-dihydroxy-4-cholesten-3-one was visualized with $I_{2}$ vapor $\left(R_{f}, 0.58\right)$ and eluted with chloroform. The radioactivity was determined and the mass of the product calculated from the specific activity of the substrate. Enzyme specific activities were expressed as picomoles of product formed per milligram protein per minute.

\section{Results}

Biliary bile acid composition. Listed in Table II are mean values for biliary bile acid and bile alcohol composition, as
Table II. Mean Biliary Bile Acid and Bile Alcohol Composition in Controls and CTX Subjects

\begin{tabular}{llc}
\hline & $\begin{array}{l}\text { Controls } \\
(n=7)\end{array}$ & $\begin{array}{l}\text { CTX } \\
(n=6)\end{array}$ \\
\hline & \% of total & \% of total \\
Cholic acid & $45 \pm 5$ & $66 \pm 19$ \\
Chenodeoxycholic acid & $43 \pm 5$ & $10 \pm 9$ \\
Deoxycholic acid & $11 \pm 10$ & $4 \pm 4$ \\
Lithocholic acid & $1 \pm 3$ & $0.2 \pm 0.4$ \\
Bile alcohol glucuronides* & - & $19.8 \pm 8.0$ \\
\hline
\end{tabular}

* The bile alcohol glucuronide fraction contained substantial amounts of $5 \beta$-cholestane-3 $3,7 \alpha, 12 \alpha, 25$-tetrol, $5 \beta$-cholestane$3 \alpha, 7 \alpha, 12 \alpha, 23 \mathrm{R}, 25$-pentol, and $5 \beta$-cholestane- $3 \alpha, 7 \alpha, 12 \alpha, 24 \mathrm{R}, 25$ pentol, as well as minor $(<1 \%)$ quantities of $5 \beta$-cholestane-

$3 \alpha, 7 \alpha, 12 \alpha, 24 \mathrm{R}$-tetrol and $5 \beta$-cholestane-3 $\alpha, 7 \alpha, 12 \alpha, 23 \mathrm{R}$-tetrol.

determined by GLC, in seven controls and six CTX subjects. Although cholic acid was the major bile acid in all individuals, the proportion of chenodeoxycholic acid in the bile of control subjects nearly equaled that of cholic acid. However, in the CTX subjects, the amount of cholic acid was two to three times higher than that of chenodeoxycholic acid. Further, the CTX bile contained significant amounts of tetra- and pentahydroxylated $\mathrm{C}_{27}$-bile alcohol glucuronides. These compounds were not detected in normal bile. The major biliary bile alcohols in these subjects have been identified as $5 \beta$-cholestane$3 \alpha, 7 \alpha, 12 \alpha, 25$-tetrol, $5 \beta$-Cholestane-3 $\alpha, 7 \alpha, 12 \alpha, 23 R, 25$-pentol, and $5 \beta$-cholestane- $3 \alpha, 7 \alpha, 12 \alpha, 24 \mathrm{R}, 25$-pentol, and are excreted conjugated with glucuronic acid. Although small amounts of $5 \beta$-cholestanetetrols hydroxylated at $\mathrm{C}_{22}$ and $\mathrm{C}_{23}$ were detected, no $5 \beta$-cholestane- $3 \alpha, 7 \alpha, 12 \alpha$-triol was present in bile of the CTX subjects. Also of interest, CTX bile contained reduced quantities of the secondary bile acids, deoxycholic acid, and lithocholic acid, which probably reflect decreased intestinal bacterial $7 \alpha$-dehydroxylase activity.

Bile acid pool sizes and production rates. In Table III, are listed the measurements of cholic acid and chenodeoxycholic acid pool sizes and production rates in three CTX and seven control subjects as determined by the isotope dilution technique according to Lindstedt (13). Mean cholic acid pool size was

Table III. Bile Acid Pool Sizes and Production Rates in CTX

\begin{tabular}{|c|c|c|c|c|}
\hline \multirow[b]{2}{*}{ Patients } & \multicolumn{2}{|l|}{ Pool size } & \multicolumn{2}{|c|}{ Production rate } \\
\hline & $\mathrm{CDCA}^{*}$ & CA $\ddagger$ & CDCA & CA \\
\hline & $\mathrm{mg} / \mathrm{kg}$ & $m g / k g$ & $m g / d$ & $m g / d$ \\
\hline $\begin{array}{l}\text { Controls } \\
\qquad(n=7)\end{array}$ & $9.3 \pm 1.2$ & $10.7 \pm 1.4$ & $150 \pm 30$ & $260 \pm 60$ \\
\hline CTX & & & & \\
\hline J.C. & 0.7 & 16.5 & 32 & 84 \\
\hline E.D.S. & 2.0 & 14.5 & 23 & 169 \\
\hline E.D.E. & 0.7 & 10.2 & 10 & 146 \\
\hline Mean $\pm S D$ & $\begin{array}{l}1.1 \pm 0.9 \\
P<0.0001\end{array}$ & $\begin{array}{l}13.7 \pm 3.2 \\
\text { NS }\end{array}$ & $\begin{array}{c}22 \pm 10 \\
P<0.001\end{array}$ & $\begin{array}{l}133 \pm 30 \\
P<0.0001\end{array}$ \\
\hline
\end{tabular}

* Chenodeoxycholic acid.

¥ Cholic acid. 
expanded slightly in the CTX subjects as compared with the control individuals $(13.7 \pm 3.2$ vs. $10.7 \pm 1.4 \mathrm{mg} / \mathrm{kg})$. In contrast, the mean pool size of chenodeoxycholic acid in the CTX subjects was reduced greatly and was only $11 \%$ as large as in controls. These values are compatible with biliary bile acid composition measurements in Table II. Primary bile acid synthesis in the CTX subjects was diminished markedly. Cholic acid formation was $\sim 50 \%$ as large as in controls, 133 $\mathrm{mg} / \mathrm{d}$ compared with $260 \mathrm{mg} / \mathrm{d}$ or $2.0 \mathrm{mg} / \mathrm{kg}$ per d vs. 3.9 $\mathrm{mg} / \mathrm{kg}$ per $\mathrm{d}$ and chenodeoxycholic acid synthesis was even more severely depressed and was $\sim 14 \%$ as great as in the controls, $22 \mathrm{mg} / \mathrm{d}(0.3 \mathrm{mg} / \mathrm{kg}$ per d) vs. $150 \mathrm{mg} / \mathrm{d}(2.2 \mathrm{mg} / \mathrm{kg}$ per $\mathrm{d})$. These results indicate that primary bile acid synthesis in CTX was reduced, with the decrease in chenodeoxycholic acid formation and pool size disproportionately greater than for cholic acid.

Cholic acid biosynthesis: hydroxylations at C-25 and C-26 by hepatic microsomal and mitochondrial preparations. To assess side-chain oxidation in cholic acid biosynthesis, measurements of $5 \beta$-cholestane- $3 \alpha, 7 \alpha, 12 \alpha$-triol-25-hydroxylase activity and $5 \beta$-cholestane- $3 \alpha, 7 \alpha, 12 \alpha$-triol-26-hydroxylase activity were carried out in microsomes and mitochondria isolated from five control and seven CTX liver specimens.

Active 25 -hydroxylation of $5 \beta$-cholestane-3 $\alpha, 7 \alpha, 12 \alpha$-triol was demonstrated in hepatic microsomes isolated from all control and CTX subjects (Table IV). The mean activity in the CTX preparations was $\sim 20 \%$ higher than in the control subjects, but the difference was not statistically significant. No microsomal 26-hydroxylase activity was detected.

$5 \beta$-Cholestane- $3 \alpha, 7 \alpha, 12 \alpha$-triol-26-hydroxylase activity was demonstrated in all mitochondrial preparations, but the activity in CTX liver was sevenfold lower than in controls. Of importance, microsomal 25 -hydroxylation of $5 \beta$-cholestane$3 \alpha, 7 \alpha, 12 \alpha$-triol was almost three times greater than the corresponding mitochondrial 26-hydroxylation in the controls and 26 times more active than in CTX. No 25-hydroxylase activity was present in the mitochondrial preparations. These results indicate a greater affinity of $5 \beta$-cholestane- $3 \alpha, 7 \alpha, 12 \alpha$ triol for microsomal 25-hydroxylation than for corresponding

Table IV. 25- and 26-Hydroxylation of 5 3 -Cholestane$3 \alpha, 7 \alpha, 12 \alpha$-triol in Cholic Acid Biosynthesis

\begin{tabular}{llc}
\hline & $\begin{array}{l}\text { Microsomal } \\
\text { 25-hydroxylation* }\end{array}$ & $\begin{array}{l}\text { Mitochondrial } \\
\text { 26-hydroxylation¥ }\end{array}$ \\
\hline & pmol product formed/mg protein per min \\
Controls $(n=5)$ & $515 \pm 64$ & $165 \pm 25$ \\
Patients (CTX) & & \\
W.H. & 582 & 26 \\
G.A. & 625 & 27 \\
P.T. & 717 & 33 \\
L.M. & 451 & 20 \\
A.B. & 538 & 15 \\
J.C. & 732 & - \\
E.D.S. & 690 & - \\
Mean \pm SD & $620 \pm 103$ & $24 \pm 7$ \\
& &
\end{tabular}

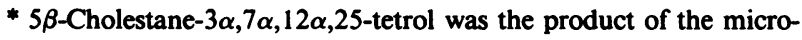
somal incubation.

$\ddagger 5 \beta$-Cholestane- $3 \alpha, 7 \alpha, 12 \alpha, 26$-tetrol was the product of the mitochondrial incubation. mitochondrial 26-hydroxylation in both control and CTX subjects. However, despite the presence of mitochondrial $5 \beta$ cholestane-3 $\alpha, 7 \alpha, 12 \alpha$-triol-26-hydroxylase activity in all hepatic specimens, significantly higher activity was found in the control subjects than in the CTX patients.

Chenodeoxycholic acid biosynthesis: hydroxylations at $C$ 25 and $C-26$ by hepatic microsomal and mitochondrial preparations. According to current views, mitochondrial 26-hydroxylation of $5 \beta$-cholestane- $3 \alpha, 7 \alpha$-diol is the key reaction in the cleavage of the cholesterol side chain in chenodeoxycholic acid synthesis. To examine this reaction, we incubated hepatic mitochondria from five control and five CTX subjects individually with $\left[7 \beta-{ }^{3} \mathrm{H}\right] 5 \beta$-cholestane- $3 \alpha, 7 \alpha$-diol under optimal conditions. The rate of formation of $5 \beta$-cholestane- $3 \alpha, 7 \alpha, 26$-triol was determined and reported in Table V. 5 5 -Cholestane$3 \alpha, 7 \alpha$-diol-26-hydroxylase activity was demonstrated in every mitochondrial preparation from both control and CTX livers. However, the mean activity in the controls was twice that found for the CTX preparations. No 25-hydroxylase activity was detected in the mitochondria.

The corresponding formation of $5 \beta$-cholestane- $3 \alpha, 7 \alpha, 25$ triol from $5 \beta$-cholestane- $3 \alpha, 7 \alpha$-diol by hepatic microsomes from control and CTX subjects was measured and also reported in Table V. In the CTX and control microsomal preparations, $5 \beta$-cholestane- $3 \alpha, 7 \alpha$-diol-25-hydroxylase activity was detected, but mean activities were 5.5 to 30 times lower than the corresponding mitochondrial $5 \beta$-cholestane- $3 \alpha, 7 \alpha$-diol-26-hydroxylase activity. These results indicate that microsomal 25 hydroxylation is not important in side-chain oxidation in chenodeoxycholic acid formation and that side-chain cleavage in chenodeoxycholic acid synthesis proceeds via $5 \beta$-cholestane$3 \alpha, 7 \alpha, 26$-triol.

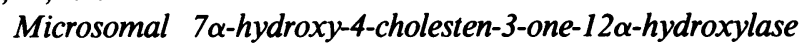
activity. Because the formation of chenodeoxycholic acid may be controlled by the amount of precursor diverted into the cholic acid synthetic pathway (12 $\alpha$-hydroxylation), measurements of $7 \alpha$-hydroxy-4-cholesten-3-one- $12 \alpha$-hydroxylase activity were made in hepatic microsomes and mitochondria isolated from two control and two CTX subjects. The results are presented in Table VI. In control incubations, average micro-

Table V. 25- and 26-Hydroxylations of 58-Cholestane$3 \alpha, 7 \alpha$-diol in Chenodeoxycholic Acid Biosynthesis

\begin{tabular}{lll}
\hline & $\begin{array}{l}\text { Microsomal } \\
\text { 25-hydroxylation* }\end{array}$ & $\begin{array}{l}\text { Mitochondrial } \\
\text { 26-hydroxylation }\end{array}$ \\
\hline & pmol product formed/mg protein per min \\
Control $(n=5)$ & $4.2 \pm 0.7$ & $126 \pm 21$ \\
Patients (CTX) & & \\
W.H. & 15.9 & 80 \\
G.A. & 13.2 & 69 \\
P.T. & 12.8 & 62 \\
L.M. & 6.4 & 46 \\
A.B. & 7.5 & 40 \\
Mean \pm SD & $11.2 \pm 4.0$ & $59 \pm 17$
\end{tabular}

* $5 \beta$-Cholestane-3 $\alpha, 7 \alpha, 25$-triol was the product of the microsomal incubation.

$\ddagger 5 \beta$-Cholestane- $3 \alpha, 7 \alpha, 26$-triol was the product of the mitochondrial incubation. 
Table VI. Microsomal 12a-Hydroxylation

of $7 \alpha$-Hydroxy-4-Cholesten-3-one

\begin{tabular}{lll}
\hline \multicolumn{3}{l}{ Product formed* } \\
\hline Controls $(n=2)$ & Average protein per min & 500 \\
Patients (CTX) & & \\
E.D.S. & & 1,700 \\
J.C. & & 1,500 \\
& Average & 1,600
\end{tabular}

* $7 \alpha, 12 \alpha$-Dihydroxy-4-cholesten-3-one was the product isolated from the incubation.

somal $7 \alpha$-hydroxy-4-cholesten-3-one-12 $\alpha$-hydroxylase activity was more than three times lower than the average value found for CTX microsomal preparations. This finding indicates that microsomal $12 \alpha$-hydroxylation is more active in CTX than control liver. Mitochondrial $12 \alpha$-hydroxylase activity was not detected in either control or CTX preparations.

\section{Discussion}

The results of the present investigation confirm and extend our knowledge regarding the nature of the bile acid synthetic defect in CTX. They conclusively establish the abnormality of biliary bile acid composition in CTX with very low amounts of chenodeoxycholic acid, reduced levels of the secondary bile acids, and the excretion of large quantities of C-12 and C-25 hydroxylated bile alcohols conjugated with glucuronic acid. All of these findings are compatible with a block in bile acid synthesis; we have suggested previously that such a defect involves the incomplete oxidation of the cholesterol side chain (4). This premise is supported by the measurements of primary bile acid pool sizes and production rates reported in Table III. In CTX, mean cholic acid synthesis was reduced by $50 \%$, while chenodeoxycholic acid production was even lower and amounted to only $14 \%$ of control values. Although the cholic acid pool was expanded modestly, chenodeoxycholic acid pool size was reduced markedly: $1.1 \pm 0.9 \mathrm{mg} / \mathrm{kg}$ in CTX subjects as compared with $9.3 \pm 1.2 \mathrm{mg} / \mathrm{kg}$ in the control subjects. We have suggested previously that many of the clinical and biochemical manifestations in CTX may be related to the extreme deficiency of chenodeoxycholic acid in the enterohepatic circulation and can be corrected by replacement therapy (7, $23,24)$.

With regard to the mechanism of reduced chenodeoxycholic acid formation in CTX, it should be noted that the 26hydroxylation pathway has been suggested to be dominant in side-chain oxidation in the biosynthesis of chenodeoxycholic acid in humans (Fig. 1). The importance of this pathway is supported by the results in Table $\mathrm{V}$, which demonstrate that mitochondrial $5 \beta$-cholestane- $3 \alpha, 7 \alpha$-diol-26-hydroxylase activity was 30 times more active than the corresponding microsomal $5 \beta$-cholestane- $3 \alpha, 7 \alpha$-diol-25-hydroxylase activity. Similar levels of mitochondrial 26-hydroxylase activity and microsomal 25hydroxylase activity for $5 \beta$-cholestane- $3 \alpha, 7 \alpha$-diol also have been reported previously for human liver by Björkhem et al. (25). Thus, 25-hydroxylation is unlikely to contribute quantitatively to side-chain oxidation in chenodeoxycholic acid syn- thesis. Recently, Oftebro et al. (10) have suggested that defective chenodeoxycholic acid synthesis in CTX may result from the total absence of mitochondrial 26-hydroxylase activity, basing this conclusion on the fact that no activity was detected in a liver specimen from a single CTX subject. Further, these investigators administered tracer doses of $5 \beta$-cholestane- $3 \alpha, 7 \alpha$ diol and $5 \beta$-cholestane- $3 \alpha, 7 \alpha, 26$-triol intravenously and found that cholestanediol was poorly transformed, while the 26hydroxylated cholestanetriol was efficiently converted into chenodeoxycholic acid (26). The combination of these findings led them to conclude that deficient mitochondrial 26-hydroxylation was the primary bile acid synthetic defect in CTX (27). However, the results of the present investigation suggest that mitochondrial 26-hydroxylation may not be rate-limiting and other factors may contribute substantially to the deficiency of chenodeoxycholic acid in the enterohepatic pool in CTX. Although chenodeoxycholic acid formation was $14 \%$ and pool size only $7 \%$ as large as controls, $5 \beta$-cholestane- $3 \alpha, 7 \alpha$-diol-26hydroxylase activity was present in all five CTX mitochondrial preparations. The mean activity of the mitochondrial 26hydroxylase was $\sim 50 \%$ lower than in controls, but still should have provided sufficient $5 \beta$-cholestane-3 $\alpha, 7 \alpha, 26$-triol for conversion into chenodeoxycholic acid so that the production rates and pool sizes ought to have been larger in the CTX subjects. However, the disproportionately small sizes of the pool and production rate suggest a diversion of precursors away from the chenodeoxycholic acid synthetic pathway. Our results support this contention by demonstrating that $7 \alpha$ hydroxy-4-cholesten-3-one-12 $\alpha$-hydroxylase activity in CTX liver microsomes was threefold higher than in control liver microsomes (Table VI). Because of increased $12 \alpha$-hydroxylation, precursors are shunted into the cholic acid biosynthetic pathway, which would accentuate the deficiency of chenodeoxycholic acid and expand the cholic acid pool that was seen in Table III. Further, although $12 \alpha$-hydroxylation of $7 \alpha$ hydroxy-4-cholesten-3-one is presumably the favored reaction (25), subsequent $12 \alpha$-hydroxylation of $5 \beta$-cholestane- $3 \alpha, 7 \alpha, 26$ triol may also occur, which in turn further favors cholic acid formation. Indeed, we have demonstrated that $5 \beta$-cholestane$3 \alpha, 7 \alpha, 26$-triol can be converted in vivo into cholic acid in both CTX and control subjects (27). However, in normal subjects in which $12 \alpha$-hydroxylase activity is low, $5 \beta$-cholestane$3 \alpha, 7 \alpha, 26$-triol was preferentially converted into chenodeoxycholic acid (27). Thus, 26-hydroxylation of $5 \beta$-cholestane$3 \alpha, 7 \alpha$-diol does not necessarily commit the precursor $5 \beta$ cholestane-3 $\alpha, 7 \alpha, 26$-triol to chenodeoxycholic acid, and thus its formation is not rate-limiting for chenodeoxycholic acid synthesis. Further, despite reduced 26-hydroxylation, chenodeoxycholic acid precursors do not accumulate in CTX. In other words, $12 \alpha$-hydroxylation either occurring before or after side-chain hydroxylation is probably the major factor determining the formation of chenodeoxycholic acid. Thus, the profound deficiency in chenodeoxycholic acid synthesis and pool size in CTX reflects the diversion of precursors (hyperactive $12 \alpha$-hydroxylation) into cholic acid pathway in combination with reduced mitochondrial 26-hydroxylation.

As concerns side-chain oxidation in cholic acid biosynthesis, both the 25- and 26-hydroxylation reaction mechanisms are presented in Fig. 2. These two pathways originate from the same intermediate, $5 \beta$-cholestane- $3 \alpha, 7 \alpha, 12 \alpha$-triol (IX) that is thought to be the obligatory precursor of cholic acid. Although both pathways have been demonstrated in humans, it has not been established which mechanism is quantitatively more 
important in cholic acid biosynthesis. In favor of the "classical" mitochondrial 26-hydroxylation pathway is the observation of Hanson et al. (28) that tracer doses of radioactive $5 \beta$-cholestane$3 \alpha, 7 \alpha, 12 \alpha, 26$-tetrol and $3 \alpha, 7 \alpha, 12 \alpha$-trihydroxycoprostanoic acid administered to humans are more efficiently converted in vivo to cholic acid than comparable tracer doses of $5 \beta$-cholestane$3 \alpha, 7 \alpha, 12 \alpha, 25$-tetrol. However, Tint et al. (29) have noted that injected doses of $5 \beta$-cholestane- $3 \alpha, 7 \alpha, 12 \alpha$-triol (an obligatory precursor) and $5 \beta$-cholestane-3 $3,7 \alpha, 12 \alpha, 25$-tetrol may not be converted quantitatively to cholic acid because of active glucuronidation and elimination in urine and bile before their entry into the cholic acid pathway. Further, in other experiments in which the quantitative conversion of $3 \alpha, 7 \alpha, 12 \alpha$-trihydroxycoprostanoic acid into cholic acid was measured in the dog by Krajer et al. (30) and in humans by Salen et al. (31) a maximum of $20 \%$ of the cholic acid formed was derived from trihydroxycoprostanoic acid. These investigators suggested that a pathway not involving 26-hydroxylated intermediates existed as the major mechanism for the cleavage of the cholesterol side chain in cholic acid biosynthesis.

In support of the alternative microsomal 25-hydroxylation pathway for side-chain oxidation in cholic acid synthesis are the observations presented in Table IV which show that microsomal $5 \beta$-cholestane- $3 \alpha, 7 \alpha, 12 \alpha$-triol-25-hydroxylase is three times more active than the corresponding mitochondrial 26-hydroxylase and that substantial 25-hydroxylase activity was present in CTX liver. Similar levels of $5 \beta$-cholestane$3 \alpha, 7 \alpha, 12 \alpha$-triol-25-hydroxylase activity have been reported in eight control subjects by Björkhem et al. (25). Further, there is plentiful formation of 25-hydroxylated bile alcohols in CTX as evidenced by the combined daily urinary and fecal excretion of over $500 \mathrm{mg} / \mathrm{d}$ of 25 -hydroxylated cholestanetetrols and cholestanepentols $(7,32)$. Thus, almost $1 \mathrm{~g}$ of cholic acid or 25-hydroxylated bile alcohols are produced in CTX. We have demonstrated previously that in CTX there is a deficiency of the microsomal enzyme that stereospecifically $24 S$ hydroxylates $5 \beta$-cholestane- $3 \alpha, 7 \alpha, 12 \alpha, 25$-tetrol. This enzymatic reaction (Fig. 2) follows 25 -hydroxylation and transforms $5 \beta$-cholestane$3 \alpha, 7 \alpha, 12 \alpha, 25$-tetrol (XIV) into $5 \beta$-cholestane- $3 \alpha, 7 \alpha, 12 \alpha$,24S,25-pentol (XV) and in CTX liver was fourfold less active than control (12). As a result of deficient $24 S$ hydroxylase activity the proximal precursor, $5 \beta$-cholestane- $3 \alpha, 7 \alpha, 12 \alpha, 25$ tetrol accumulates and is either glucuronidated and excreted in the bile or is further transformed by microsomal hydroxylations at $\mathrm{C}-22, \mathrm{C}-23$, or $\mathrm{C} 24 \mathrm{R}$ into $5 \beta$-cholestanepentols $(7$, 32 ). Further, the results of the present investigation (active 25hydroxylation combined with inactive 26-hydroxylation) confirm that side-chain oxidation in cholic acid formation in CTX occurs via the 25 -hydroxylation pathway. This fact is consistent with our earlier study that demonstrated a precursor-product relationship between $5 \beta$-cholestane- $3 \alpha, 7 \alpha, 12 \alpha, 25$-tetrol and cholic acid in CTX (11). However, right now we cannot conclude that this is the sole bile acid synthetic defect in the cholic acid pathway in CTX because 26-hydroxylation of $5 \beta$ cholestane $3 \alpha, 7 \alpha, 12 \alpha$-triol by hepatic mitochondria was extremely low (Table IV), as noted previously by Oftebro et al. (9). Thus, it is not possible to define the enzymatic defect in cholic acid synthesis in CTX with certainty until the quantitative mechanism for side-chain cleavage in cholic acid synthesis is known.

In summary, certain generalizations about side-chain cleavage in bile acid synthesis may be derived from these studies. First, side-chain oxidation in chenodeoxycholic acid synthesis probably occurs via 26-hydroxylated and not 25-hydroxylated intermediates, because microsomal 25-hydroxylation of $5 \beta$ cholestane- $3 \alpha, 7 \alpha$-diol is extremely low. Second, the marked deficiency of chenodeoxycholic acid in the enterohepatic pool and reduced synthesis in CTX probably reflect increased $12 \alpha-$ hydroxylation combined with a partial reduction in mitochondrial 26-hydroxylation of 5 $\beta$-cholestane-3 $\alpha, 7 \alpha$-diol. Third, sidechain oxidation in cholic acid synthesis in CTX occurs mainly via the 25-hydroxylation pathway. Whether the 25-hydroxylation pathway contains the specific enzymatic defect in bile acid synthesis (deficiency of microsomal $5 \beta$-cholestane$3 \alpha, 7 \alpha, 12 \alpha, 25$-tetrol-24S-hydroxylase), as suggested by Salen et al. (12), or is secondary to deficient mitochondrial 26-hydroxylation, as suggested by Oftebro et al. (9), remains to be established.

\section{Acknowledgments}

The excellent technical assistance of Mr. Jeffrey Speck, Ms. Barbara Allen, and Ms. Barbara Rouse is greatly appreciated. We are grateful to Drs. Thomas W. Meriwether III, John D. Hughes, William Harlan, Gregory Bennett, and Ernst J. Schaefer for referral of the CTX patients.

This work was supported in part by the Veterans Administration Research Service, by U. S. Public Health Service grants HL 17818, AM 18707, and AM 26756, and by a grant from The Herman Goldman Foundation.

\section{References}

1. Danielsson, H. 1973. Mechanisms of bile acid biosynthesis. In The Bile Acids: Chemistry, Physiology and Metabolism. Physiology and Metabolism, Vol. 2. P. P. Nair and D. Kritchevsky, editors. Plenum Publishing Corporation, New York. 1-32.

2. Salen, G., S. Shefer, and V. D. Berginer. 1983. Familial disease with storage of sterols other than cholesterol: cerebrotendinous xanthomatosis and sitosterolemia with xanthomatosis. In The Metabolic Basis of Inherited Disease. J. B. Stanbury, J. B. Wyngaarden, D. S. Fredrickson, J. L. Goldstein, and M. S. Brown, editors. McGraw-Hill, New York. 713-730.

3. Salen, G. 1971. Cholestanol deposition in cerebrotendinous xanthomatosis: a possible mechanism. Ann. Intern. Med. 75:843-851.

4. Setoguchi, T., G. Salen, G. S. Tint, and E. H. Mosbach. 1974. A biochemical abnormality in cerebrotendinous xanthomatosis: in complete oxidation of the cholesterol side chain. J. Clin. Invest. 53: 1393-1401.

5. Shefer, S., B. Dayal, G. S. Tint, G. Salen, and E. H. Mosbach. 1975. Identification of pentahydroxy bile alcohols in cerebrotendinous xanthomatosis. J. Lipid Res. 16:280-286.

6. Hoshita, T., M. Yosuharu, M. Une, A. Kibe, E. Itogu, S. Kito, and T. Kuramoto. 1980. Occurence of bile alcohol glucuronides in bile of patients with cerebrotendinous xanthomatosis. J. Lipid Res. 21: 1015-1021.

7. Wolthers, B. C., M. Volmer, J. van der Molen, B. J. Koopman, A. E. J. de Jager, and R. J. Waterreus. 1983. Diagnosis of cerebrotendinous xanthomatosis (CTX) and effect of chenodeoxycholic acid therapy by analysis of urine using capillary gas chromatography. Clin. Chim. Acta. 131:53-65.

8. Salen, G., and S. M. Grundy. 1973. The metabolism of cholestanol, cholesterol, and bile acids in cerebrotendinous xanthomatosis. J. Clin. Invest. 52:2822-2835.

9. Oftebro, H., I. Björkhem, S. Skrede, H. Schreiner, and J. I. Pedersen. 1980. Cerebrotendinous xanthomatosis, a defect in mitochondrial 26-hydroxylation required for normal biosynthesis of cholic acid. J. Clin. Invest. 65:1418-1430.

10. Oftebro, H., I. Björkhem, F. C. Stormer, and J. I. Pedersen. 1981. Cerebrotendinous xanthomatosis: defective liver mitochondrial 
hydroxylation of chenodeoxycholic acid precursors. J. Lipid Res. 22: $632-640$

11. Salen, G., S. Shefer, T. Setoguchi, and E. H. Mosbach. 1975. Bile alcohol metabolism in man: conversion of $5 \beta$-cholestane-3 $\alpha, 7 \alpha, 12 \alpha$, 25-tetrol to cholic acid. J. Clin. Invest. 56:226-231.

12. Salen, G., S. Shefer, F. W. Chen, B. Dayal, A. K. Batta, and G. S. Tint. 1979. Cholic acid biosynthesis. The enzymatic defect in cerebrotendinous xanthomatosis. J. Clin. Invest. 63:38-44.

13. Lindstedt, S. 1957. The turnover of cholic acid in man. Acta Physiol. Scand. 40:1-9.

14. Björkhem, I., H. Danielsson, C. Issidorides, and A. Kallner. 1965. On the synthesis and metabolism of cholest-4-en-7-ol-3-one. Acta Chem. Scand. 19:2151-2154.

15. Bergström, S., and L. Krabisch. 1957. Preparation of some hydroxy coprostanes, $3 \alpha, 7 \alpha$ - and $3 \alpha, 12 \alpha$-dihydroxy coprostane. Acta Chem. Scand. 11:1067.

16. Björkhem, I., and J. Gustafsson. 1973. $\omega$-Hydroxylation of steroid side chain in biosynthesis of bile acids. Eur. J. Biochem. 36: 201-212.

17. Dayal, B., S. Shefer, G. S. Tint, G. Salen, and E. H. Mosbach. 1976. Synthesis of $5 \beta$-cholestane- $3 \alpha, 7 \alpha, 12 \alpha, 25$-tetrol and $5 \beta$-cholestane$3 \alpha, 7 \alpha, 12 \alpha, 24 \xi, 25$-pentol. J. Lipid Res. 17:74-77.

18. Batta, A. K., G. Salen, and S. Shefer. 1980. Thin-layer chromatography of bile alcohols, bile acids, and conjugated bile acids. J. Liq. Chromatogr. 3(12):1865-1879.

19. Shefer, S., F. W. Cheng, B. Dayal, S. Hauser, G. S. Tint, G. Salen, and E. H. Mosbach. 1976. A 25-hydroxylation pathway of cholic acid biosynthesis in man and rat. J. Clin. Invest. 57:897-903.

20. Shefer, S., F. W. Cheng, A. K. Batta, B. Dayal, G. S. Tint, and G. Salen. 1978. Biosynthesis of chenodeoxycholic acid in man: stereospecific side-chain hydroxylations of $5 \beta$-cholestane-3 $\alpha, 7 \alpha$-diol. J. Clin. Invest. 62:539-545.

21. Lowry, O. H., N. J. Rosebrough, A. L. Farr, and R. J. Randall. 1951. Protein measurement with the Folin phenol reagent. J. Biol. Chem. 193:265-275.

22. Nicolau, G., B. I. Cohen, G. Salen, and E. H. Mosbach. 1976. Studies in the 12- and 26-hydroxylation of bile alcohols by rabbit liver mitochondria. Lipids. 2:148-152.

23. Berginer, V. M., G. Salen, and S. Shefer. 1984. Long-term treatment of cerebrotendinous xanthomatosis with chenodeoxycholic acid. N. Engl. J. Med. 311:1649-1652.

24. Koopman, B. J., J. van der Molen, B. C. Wolthers, A. E. J. de Jager, R. J. Waterreus, and C. H. Gips. 1984. Capillary gas chromatography determination of cholestanol/cholesterol ratio in biological fluids. Its potential usefulness for the follow-up of liver disease and its lack of specificity in diagnosing CTX (cerebrotendinous xanthomatosis). Clin. Chim. Acta. 137:305-315.

25. Björkhem, I., J. Gustafsson, G. Johansson, and B..Persson. 1975. Biosynthesis of bile acids in man. Hydroxylation of the $C_{2 T}$ steroid side chain. J. Clin. Invest. 55:478-486.

26. Björkhem, I., O. Fauson, G. Hopen, H. Oftebro, J. I. Pedersen, and S. Skrede. 1983. Role of the 26-hydroxylase in the biosynthesis of bile acids in the normal state and in cerebrotendinous xanthomatosis. J. Clin. Invest. 71:142-143.

27. Salen, G., S. Shefer, E. H. Mosbach, S. Hauser, B. I. Cohen, and G. Nicolau. 1979. Metabolism of potential precursors of chenodeoxycholic acid in cerebrotendinous xanthomatosis (CTX). J. Lipid Res. 20:22-30.

28. Hanson, R. F., A. B. Staples, and G. C. Williams. 1979. Metabolism of $5 \beta$-cholestane- $3 \alpha, 7 \alpha, 12 \alpha, 26$-tetrol and $5 \beta$-cholestane$3 \alpha, 7 \alpha, 12 \alpha, 25$-tetrol into cholic acid in normal human subjects. $J$. Lipid Res. 20:489-493.

29. Tint, G. S., G. Salen, B. Dayal, A. K. Batta, and S. Shefer. 1984. Incomplete transformation of precursors to cholic acid and their excretion in bile and urine. Clin. Res. 32:492a. (Abstr.)

30. Krajer, L. E., G. C. Williams, P. Sczepanik, S. Silvis, and R. F. Hanson. 1979. Formation of cholic acid via $3 \alpha, 7 \alpha, 12 \alpha$-trihydroxy$5 \beta$-cholestan-26-oic acid in the dog. Biochem. Biophys. Acta. 573:430 439.

31. Salen, G., A. K. Batta, G. S. Tint, B. Dayal, and S. Shefer. 1983. The transformation of $3 \alpha, 7 \alpha, 12 \alpha$-trihydroxycoprostanoic acid to cholic acid in humans. In Bile Acids and Cholesterol in Health and Disease. G. Paumgartner, A. Stiehl, and W. Gerok, editors. MTP Press Ltd., Lancaster, England. 91-98.

32. Karlaganis, G., V. Karlaganis, and J. Sjövall. 1983. Bile alcohol glucuronides in urine: secondary metabolites of intermediates in the formation of bile cholesterol. In Bile Acids and Cholesterol in Health and Disease. G. Paumgartner, A. Stiehl, and W. Gerok, editors. MTP Press Ltd., Lancaster, England. 119-127. 